\title{
STABILITY OF A MULTI-MACHINE POWER SYSTEM EQUIPPED WITH LQG CONTROLLERS
}

\author{
Ahmed Said Oshaba1, 2 \\ 1-Power Electronics \& Energy Conversion Dep., Electronics Research Institute (ERI) \\ 2. Jizan University, Faculty of Engineering, Electrical Engineering Department, KSA \\ E-mail: oshaba68@hotmail.com,
}

\begin{abstract}
This paper presents the design of a novel control strategy of a Power System Stabilizer (PSS) for generators in multimachine electric power systems using the Linear Quadratic Gawssian (LQG) control technique. The controller combines both the excitation and governor control loops. The technique is applied using a sample power system which includes a number of generators connected to a large power system. An optimal full state controller has been designed and a state observer is included using Kalman Filter theory. A comprehensive stability analysis and time domain performance analysis of the system with the new controller have been presented. The results prove the robustness and powerful of proposed LQG controller in improve stability margins and adding positive with a noticeable reduction in settling time.
\end{abstract}

Key-word:- LQR controller, LQG controller, power system stabilizer and multi-machine power system

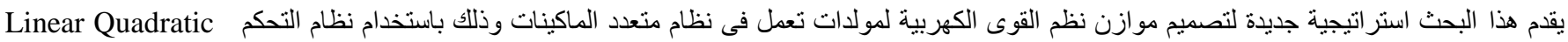

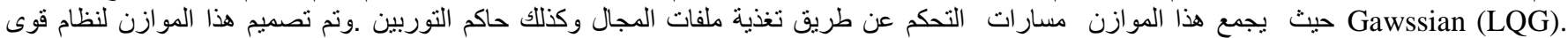

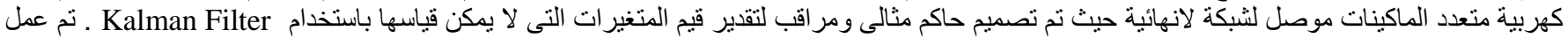

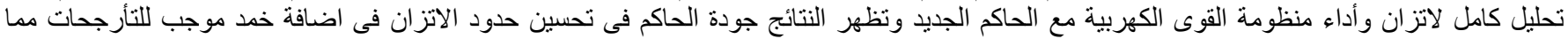

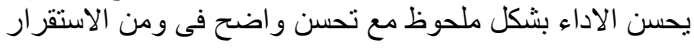

\section{Introduction}

Many papers have been published on the synthesis of the power system stabilizer (PSS) control system. Some approach it by complex frequency methods using the concept of synchronizing and damping torques $[1,2]$, some by optimal control methods and also, by using pole placement methods [35]]. In control system designed a satisfactory controller cannot be obtained by considering the internal stability objective alone. The interconnected power system can be achieved by conventional controller as[1,3]. A brief overview of the theoretical foundation of $H_{\infty}$ synthesis is introduced in [7]. The $H_{\infty}$ formulation and solution procedures are explained, and guidelines on how to choose proper weighting functions that reflect the robustness and performance goals are given in $[8,9,10] . H_{\infty}$ Synthesis is carried out in two stages.

First, in what is called the $H_{\infty}$ formulation procedure, robustness to modeling errors and weighting the appropriate input-output transfer functions usually reflects performance requirements. The weights and the dynamic model of the power system are then augmented into an $H_{\infty}$ standard plant [9]. Second, in what is called the $H_{\infty}$ solution procedure, the standard plat is programmed into a computer aided design software, such as MATLAB[11], and the weights are iteratively modified until an optimal controller that satisfies the $H_{\infty}$ optimization problem is found. Time response simulations are used to validate the results obtained and to illustrate the dynamic system response to state disturbances. The effectiveness of such 
controllers is examined at different extreme operating conditions. Using the linear quadratic regulator (LQR)

The present paper used the LQR approach and Kalman filter to design a robust LQG power system stabilizer for stabilization the dynamic responses at different operating conditions.

\section{Power System Model}

for comparison with the proposed robust $H_{\infty}$ controller.

Two power system models are studying in this research as follow:

\subsection{Single machine model}

A synchronous machine connected to infinite bus via a transmission line is used as shown in the block diagram of Fig.1 . The state space formulation can be obtained as follows:

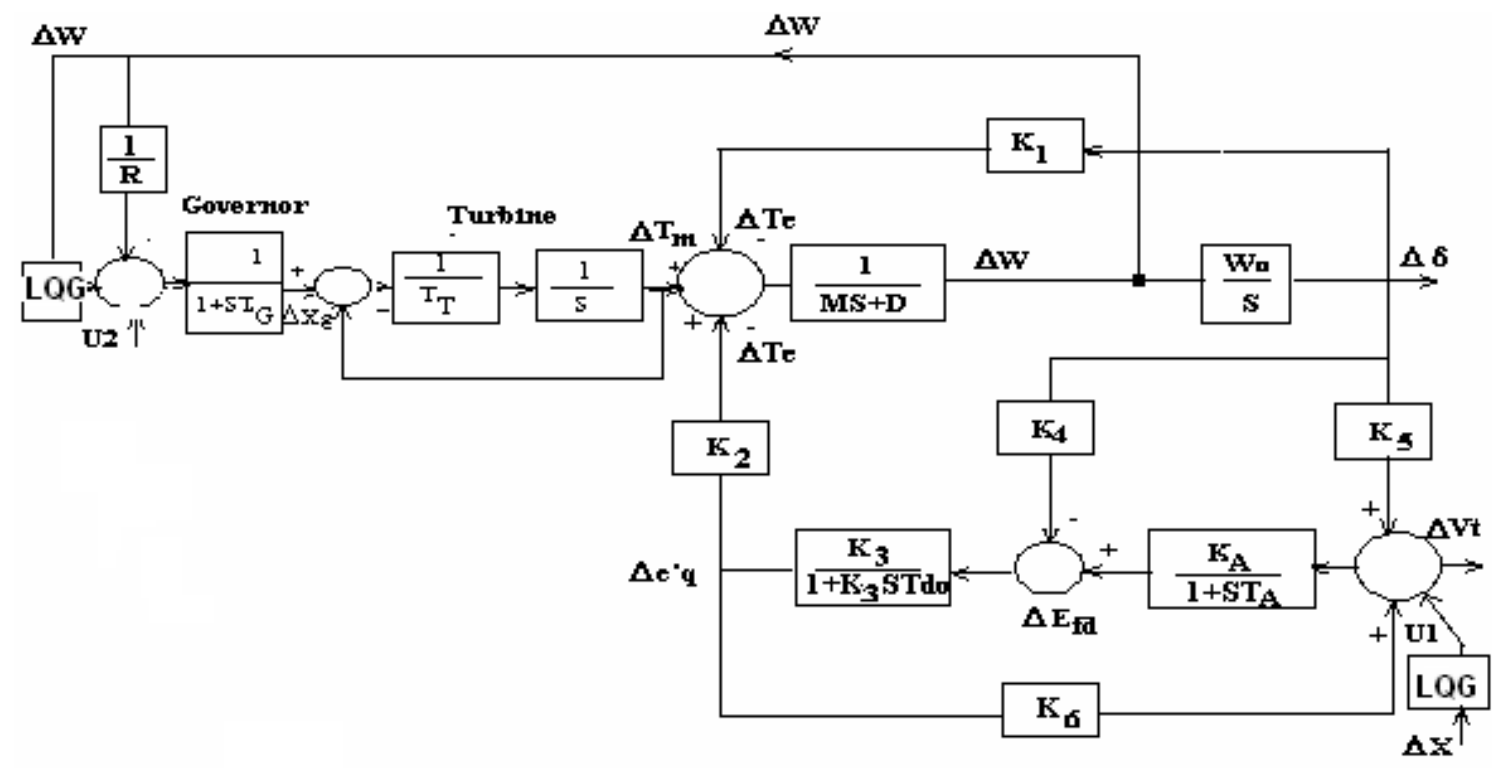

Fig.1: The block diagram of single machine power system.

\section{Steady-state Representation}

$\Delta \dot{\delta}=\Delta w$

$\Delta w=-\left(K_{1} / M\right) \Delta \delta-(D / M) \Delta w-\left(K_{2} / M\right) \Delta E^{\prime} q$

$+(1 / M) \Delta T_{m}-(1 / M) \Delta P_{d}$

$\Delta \dot{E}_{q}=-\left(K_{4} / T^{\prime} d o\right) \Delta \delta-\left(1 / K_{3} T^{\prime} d o\right) \Delta E^{\prime} q$

$+\left(1 / T^{\prime} d o\right) \Delta E_{f d}$

$\Delta \dot{T}_{m}=-\left(1 / T_{t}\right) \Delta T_{m}+\left(1 / T_{t}\right) \Delta P_{g}$

$$
\begin{aligned}
& \Delta \dot{P}_{g}=-\left(1 / R T_{g}\right) \Delta w-\left(1 / T_{g}\right) \Delta P_{g}+\left(1 / T_{g}\right) U_{2} \\
& \Delta \dot{E}_{f d}=-\left(1 / T_{A}\right) \Delta E_{f d}-\left(K_{A} K_{5} / T_{A}\right) \Delta \delta \\
& -\left(K_{A} K_{6} / T_{A}\right) \Delta e^{\prime} q+\left(K_{A} / T_{A}\right) U_{1}
\end{aligned}
$$

In a matrix form as follows:

$$
\Delta \dot{X}=A \Delta X+B \Delta U+\eta \Delta P_{d}
$$

where;

$$
\Delta X=\left[\begin{array}{llllll}
\Delta \delta & \Delta \omega & \Delta E_{q}^{\prime} & \Delta T_{m} & \Delta P_{g} & \Delta E_{f d}
\end{array}\right]^{t}
$$


$A=\left[\begin{array}{cccccc}0 & w o & 0 & 0 & 0 & 0 \\ \frac{-K_{1}}{M} & \frac{-D}{M} & \frac{-K_{2}}{M} & \frac{1}{M} & 0 & 0 \\ \frac{-K_{4}}{T_{d o}^{\prime}} & 0 & \frac{-1}{\left(K_{3} T_{d o}^{\prime}\right)} & 0 & 0 & \frac{1}{T_{d o}^{\prime}} \\ 0 & 0 & 0 & \frac{-1}{T_{t}} & \frac{1}{T_{t}} & 0 \\ 0 & \frac{-1}{R T_{g}} & 0 & 0 & \frac{-1}{T_{g}} & 0 \\ \frac{-K_{A} K_{5}}{T_{A}} & 0 & \frac{-K_{A} K_{6}}{T_{A}} & 0 & 0 & \frac{-1}{T_{A}}\end{array}\right]$

$B=\left[\begin{array}{l}B_{1} \\ B_{2}\end{array}\right]^{t}=\left[\begin{array}{cccccc}0 & 0 & 0 & 0 & 0 & \frac{K_{A}}{T_{A}} \\ 0 & 0 & 0 & 0 & \frac{1}{T_{g}} & 0\end{array}\right]^{t}$
$\Delta U=\left[\begin{array}{ll}\Delta U_{1} & \Delta U_{2}\end{array}\right]^{t} \eta=\left[\begin{array}{llllll}0 & \frac{-1}{M} & 0 & 0 & 0 & 0\end{array}\right]^{t}$

\subsection{Multi-machine model}

The power system model used consists of three synchronous machines connected to infinite bus and its dynamic performance is represented in the state variables form. The single line diagram model for the system is shown in the Fig.2 and is based upon the following assumptions

1- Saturation is neglected,

2- Armature transformer voltage is neglected,

3- Damper winding effect is neglected.

Once the $\mathrm{A}, \mathrm{B}$ and $\mathrm{C}$ matrices are determined, applying the Linear Quadratic Gaussian LQG controller on it. The multi machine power system data and load flow are displayed in tables $1,2 .[2,12]$

Table 1: The Multi-machine Power System Data

\begin{tabular}{llllllllc}
\hline M/C & \multicolumn{8}{c}{ Machine data } \\
& \multicolumn{10}{c}{$\mathrm{X}_{\mathrm{q}}$} & $\mathrm{X}_{\mathrm{j}}$ & $\mathrm{T}_{\mathrm{do}}$ & $\mathrm{H}$ & $\mathrm{K}_{\mathrm{A}}$ & $\mathrm{T}_{\mathrm{A}}$ & Base quantities \\
\cline { 2 - 9 } & $\mathrm{X}_{\mathrm{d}}$ & & & & & & \\
\hline 1 & 1.68 & 1.66 & 0.32 & 4.0 & 2.31 & 40.0 & 0.05 & $360 \mathrm{MVA}, 13.8 \mathrm{KV}$ \\
2 & 0.88 & 0.53 & 0.33 & 8.0 & 3.40 & 45.0 & 0.05 & $503 \mathrm{MVA}, 13.8 \mathrm{KV}$ \\
3 & 1.02 & 0.57 & 0.20 & 7.76 & 4.63 & 50.0 & 0.05 & $1673 \mathrm{MVA}, 13.8 \mathrm{KV}$
\end{tabular}

Table 2: The Multi-machine load flow data.

\begin{tabular}{lllll}
\hline Bus & Power flow & $\mathrm{Q}_{\mathrm{o}} \mathrm{MVA}$ & $\mathrm{V}_{\text {to }}$ pu. & $\delta_{\mathrm{o}}$. degrees \\
\hline 1 & $\mathrm{P}_{\mathrm{o}}, \mathrm{MW}$ & & & \\
\hline 2 & 26.5 & 37.0 & 1.3 & 10 \\
3 & 518 & -31.5 & 1.025 & 32.52 \\
4 & 1582 & -69.9 & 1.3 & 45.82 \\
\hline
\end{tabular}

Each plant is represented by a $4^{\text {th }}$-order generator equipped with a static exciter. The state equation of this system is given by

$$
\dot{X}=A X+B U
$$


Where

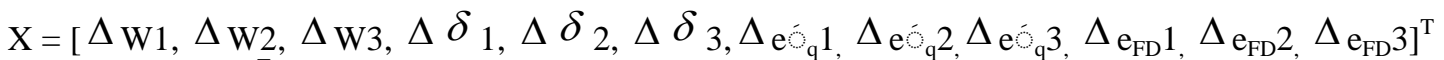

$\mathrm{U}=\left[\begin{array}{lll}\mathrm{u}_{1} & \mathrm{u}_{2} & \mathrm{u}_{3}\end{array}\right]^{\mathrm{T}}$

$\mathrm{A}=$ Matrix system

$\mathrm{B}=$ input matrix

Is the input vector .The system $\mathrm{A}$ and $\mathrm{B}$ are given as follows

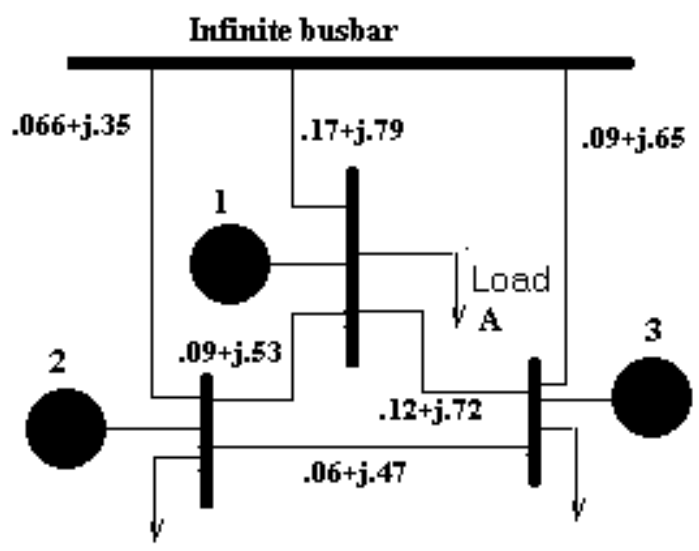

Load B

Load C

Fig.2: three machine-infinite bus systems.

$A=\left[\begin{array}{cccccccccccc}-0.039 & 0.004 & 0.02 & -0.147 & 0.022 & 0.046 & -0.013 & 0 & 0.003 & 0.0 & 0.0 & 0.0 \\ -0.034 & 0.032 & -0.028 & 0.004 & -0.149 & 0.079 & -0.00645 & -0.008 & 0.0 & 0.0 & 0.0 & 0.0 \\ -0.017 & -0.01 & -0.017 & 0.001 & 0.017 & -0.056 & -0.003 & 0.0 & -0.009 & 0.0 & 0.0 & 0.0 \\ 377 & 0.0 & 0.0 & 0.0 & 0.0 & 0.0 & 0.0 & 0.0 & 0.0 & 0.0 & 0.0 & 0.0 \\ 0.0 & 377 & 0.0 & 0.0 & 0.0 & 0.0 & 0.0 & 0.0 & 0.0 & 0.0 & 0.0 & 0.0 \\ 0.0 & 0.0 & 377 & 0.0 & 0.0 & 0.0 & 0.0 & 0.0 & 0.0 & 0.0 & 0.0 & 0.0 \\ -3.393 & 0.754 & 1.131 & -0.266 & -0.087 & -0.25 & -0.922 & 0.024 & 0.072 & 1 & 0.0 & 0.0 \\ 1.131 & -1.885 & 0.754 & 0.121 & -1.6 & 0.46 & 0.021 & -0.21 & 0.06 & 0.0 & 1 & 0.0 \\ 0.0 & 0.0 & -1.131 & 0.083 & 0.22 & -1.2 & -0.002 & 0.011 & -0.197 & 0.0 & 0.0 & 1.0 \\ -309.14 & -91.99 & -1675 & -30.1 & 24.599 & 62.051 & -60.943 & -3.501 & -10.194 & -20 & 0.0 & 0.0 \\ -64.47 & -516.11 & -171.91 & -18.48 & 106.09 & 16.99 & -12.55 & -21.67 & -11.41 & 0.0 & -20 & 0.0 \\ -33.93 & -46.37 & -893.49 & -10.1 & 1.7 & 70.1 & -6.78 & -2.1 & -54.4 & 0.0 & 0.0 & -20\end{array}\right]$

$B=\left[\begin{array}{cccccccccccc}O & 0 & 0 & 0 & 0 & 0 & 0 & 0 & 0 & 0 & 0 & 1000 \\ O & 0 & 0 & 0 & 0 & 0 & 0 & 0 & 0 & 0 & 900 & 0 \\ 0 & 0 & 0 & 0 & 0 & 0 & 0 & 0 & 0 & 800 & 0 & 0\end{array}\right]^{T}$ 


\section{Control Philosophy and Design}

The structure of the optimal Linear Quadratic Gaussian (LQG) stabilizer is shown in Figs.3 and 4. It consists of combination of an optimal LQR control and a Kalman filter. The LQG stabilizer is designed as follows:

1- Firstly an optimal full state regulator $L Q R$ for a linear plant is designed.

2- An state observer is designed using Kalman filter theory with a known input $\mathrm{u}(\mathrm{t})$, a measured output $\mathrm{y}(\mathrm{t})$ and white noises $\mathrm{v}(\mathrm{t})$ and $\mathrm{z}(\mathrm{t})$.

3- The LQG PSS Combine both the LQR and State Observor

4- The optimal regulator feedback gain matrix, K, and the Kalman filter gain matrix, L, are used to complete closed compensator system LQG as follows:

From Eqn.( 10) get optimal regulator gain matrix $\boldsymbol{K}_{L Q R}$. Calculate the Kalman filter gain as follows. Let the system as

$$
\begin{aligned}
& x=A x+B u+G w \quad \text { \{State equation } \\
& y=C x+D u+v \quad \text { \{Measurements }
\end{aligned}
$$

with unbiased process noise $\mathbf{w}$ and measurement noise $\mathbf{v}$ with covariance's

$$
\begin{gathered}
\mathrm{E}\left\{\mathrm{ww}^{\prime}\right\}=\mathrm{Q}, \quad \mathrm{E}\left\{\mathrm{vv}^{\prime}\right\}=\mathrm{R}, \quad \mathrm{E}\left\{\mathrm{wv}^{\prime}\right\}=\mathrm{N}, \\
{[L, P, E]=L Q E(A, G, C, Q, R, N)}
\end{gathered}
$$

Returns the observer gain matrix $\boldsymbol{L}$ such that the stationary Kalman filter.

$$
x \_e=A x \_e+B u+L\left(y-C x \_e-D u\right)
$$

Produces an optimal state observer which estimate $\boldsymbol{x} \_\boldsymbol{e}$ of $\boldsymbol{x}$ using the sensor measurements $\boldsymbol{y}$. The resulting Kalman estimator can be formed with estimator. The noise crosscorrelation $\boldsymbol{N}$ is set to zero when omitted. Also returned are the solution $\boldsymbol{P}$ of the associated Riccati equation.

$A P+P A^{\prime}-\left(P C^{\prime}+G^{*} N\right) R\left(C P+N^{\prime *} G^{\prime}\right)+G^{*} Q^{*} G^{\prime}=0$

and the estimator poles $\boldsymbol{E}=\boldsymbol{E} \boldsymbol{I} \boldsymbol{G}\left(\boldsymbol{A}-\boldsymbol{L}^{*} \boldsymbol{C}\right)$.

Using MATLAB function readymade command reg to construct a state-space model of the optimal compensator LQG, given a state-space model of the plant, sysp, the optimal regulator feedback gain matrix $\boldsymbol{K}$, and the Kalman filter gain matrix $\boldsymbol{L}$. This command is used as follows:

$$
\text { sys_closed }=\operatorname{reg}\left(\operatorname{sysp}, K_{L Q R}, L\right)
$$

Where; sys_closed is the state-space model of the LQG compensator. The final, get the system overall feedback sys $C L$ as:

$$
\text { sysCL }=\text { feedback }(\text { sysp, }, \quad \text { sys_closed })(16)
$$

Where, sysCL is the state-space of LQG plus state-space of system with open-loop

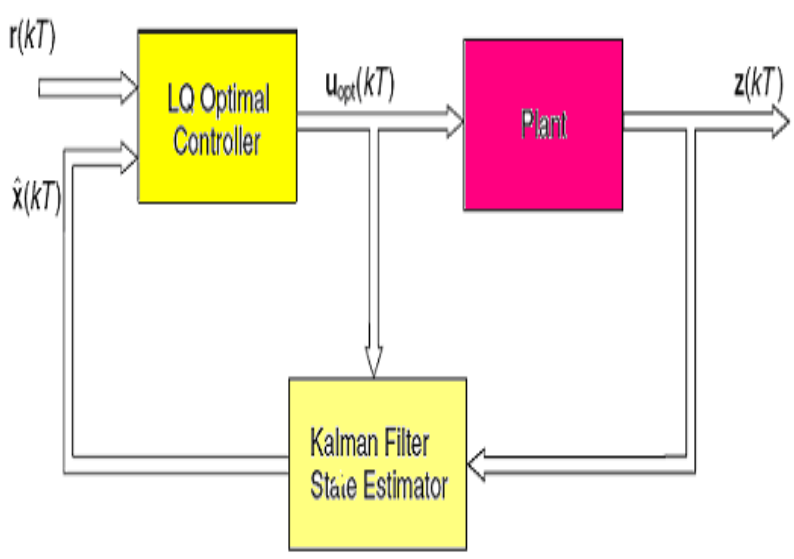

Fig. 3: Linear Quadratic Gaussian (LQG) control system.

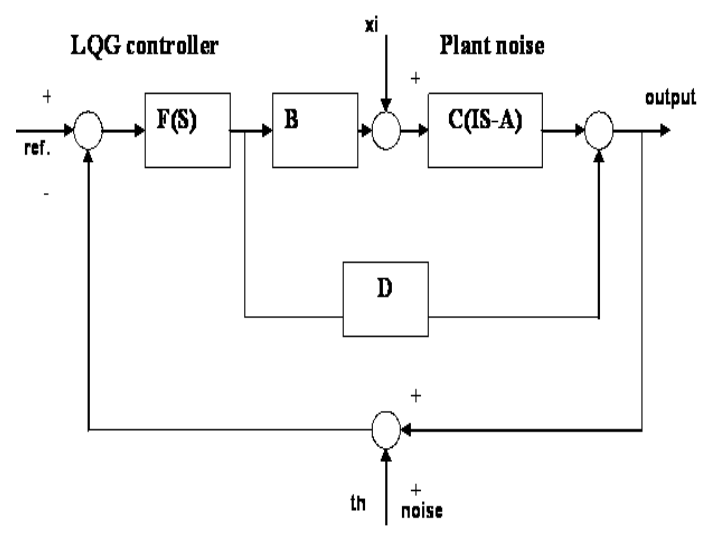

Fig.4: The LQG synthesis. 


\subsection{Optimal LQR control design}

The object of the optimal control design is determining the optimal control law $u(t, x)$ which can transfer system from its initial state to the final state such that given quadratic performance index is minimized.

$$
\left[K_{L Q R}, S, E\right]=\operatorname{lqr}(A, B, Q, R, N)
$$

Where: $\mathrm{Q}$ is positive semi definite matrix and $\mathrm{R}$ is real symmetrical matrix. The problem is to find the vector feedback $K$ of control law, by choosing matrix $\mathrm{Q}$ and $\mathrm{R}$ to minimize the quadratic performance index $\mathrm{J}$ is described by :

$$
J=\int_{0}^{\infty}\left(\Delta x^{t} Q \Delta x+\Delta u^{t} R^{-1} \Delta u\right) d t
$$

The optimal control law is written as

$$
\begin{aligned}
& \Delta \mathrm{u}(\mathrm{t})=\mathrm{K} \Delta \mathrm{x}(\mathrm{t}) \\
& K_{L Q R}=-R^{-1} B^{t} P
\end{aligned}
$$

The matrix $P$ is positive definite, symmetric solution to the matrix Riccati equation, which has written as:

$P A+A^{t} P+Q-P B R^{-1} B^{t} P=0$

\subsection{State estimation using Kalman filter}

Alternatively, it is possible to estimate the whole state vector by using a Kalman filter. The Kalman filter optimally filters noise in the measured variables and allows the estimation of unmeasured states. The Kalman filter uses a model of the system to find a state estimate ${ }^{\wedge} \mathbf{x}(\mathbf{t})$ by integrating the following state observer equation:

$$
\dot{\hat{x}}=A \hat{x}+B u+K_{f}\left(y_{m}-C \hat{x}\right)
$$

where $y_{m}$ is the measured output and $\mathrm{K}_{\mathrm{f}}$ is the Kalman filter gain. The Kalman filter assumes that the measurements obey the following model:

$$
\begin{aligned}
\dot{x} & =A x+B u+G w \\
y_{m} & =C x+v
\end{aligned}
$$

Where $\mathbf{G}$ is a noise distribution matrix, $\boldsymbol{w}$ and $\boldsymbol{v}$ are white noise processes. $\mathrm{v}$ is the measurement noise and is assumed to have a covariance matrix $\boldsymbol{R}_{f}$. W is known as process noise and is assumed to have a covariance matrix $\boldsymbol{Q}_{f}$. The Kalman filter gain $\boldsymbol{K}_{f}$ is found as follows:

$$
K_{f}=P C^{T} R_{f}^{-1}
$$

where $\boldsymbol{P}$ is the solution of the algebraic Ricatti equation:

$$
A P+P A^{T}+G Q_{f} G^{T}-P C^{T} R_{f}^{-1} C P=0
$$

If we use the control law given in Equation 17 with a state estimate obtained using a Kalman filter, then we are using the LQG (Linear Quadratic Gaussian) control law:

$$
u=-K \hat{x}
$$

\section{Digital Simulation Results}

\subsection{Simulation of single machine model}

From LQR control (Eqn. 10), the feedback gain and solution of Reccati equation are :

$$
K_{L Q R}=\left[\begin{array}{rrrrrr}
0.0655 & -3.9708 & 0.4493 & 0.0040 & -0.1071 & 0.0831 \\
-0.0214 & 1.7302 & -0.1779 & -0.0015 & 0.0413 & -0.0032
\end{array}\right]
$$

$$
S=1000 *\left[\begin{array}{cccccc}
0.0004 & 0.0025 & -0.0005 & 0.0000 & -0.0002 & 0.0000 \\
0.0025 & 1.6524 & -0.1226 & -0.0005 & 0.0138 & -0.0010 \\
-0.0005 & -0.1226 & 0.0293 & -0.0001 & -0.0014 & 0.0001 \\
0.0000 & -0.0005 & -0.0001 & 0.0000 & -0.0000 & 0.0000 \\
-0.0002 & 0.0138 & -0.0014 & -0.0000 & 0.0003 & -0.0000 \\
0.0000 & -0.0010 & 0.0001 & 0.0000 & -0.0000 & 0.0000
\end{array}\right]
$$

From LQG and Kalman filter control (Eqn. 13), the observer gain matrix $\boldsymbol{L}$ and solution of reccati equation $\mathrm{P}$ are :

$$
L=\left[\begin{array}{cl}
14.4339 & 0.2762 \\
0.2762 & 0.0156 \\
-0.1471 & -0.0007 \\
8.7476 & 0.0534 \\
0.0390 & 0.0006 \\
-0.1305 & -0.0043
\end{array}\right]
$$


Ahmed Said Oshaba, " Stability Of A Multi-Machine Power System Equipped With Lqg Controllers."

$P=\left[\begin{array}{cccccc}21.7952 & 0.4171 & -0.2221 & 13.2088 & 0.0589 & -0.1971 \\ 0.4171 & 0.0235 & -0.0010 & 0.0806 & 0.0009 & -0.0065 \\ -0.2221 & -0.0010 & 0.0559 & -0.7356 & -0.0006 & 0.0010 \\ 13.2088 & 0.0806 & -0.7356 & 17.4002 & 0.0380 & -0.0708 \\ 0.0589 & 0.0009 & -0.0006 & 0.0380 & 0.0326 & -0.0025 \\ -0.1971 & -0.0065 & 0.0010 & -0.0708 & -0.0025 & 0.0115\end{array}\right]$

Table 3: Eigen values calculation with and without controllers of single machine power system.

\begin{tabular}{|c|c|c|c|c|}
\hline $\begin{array}{l}\text { Operating } \\
\text { point }\end{array}$ & $\begin{array}{l}\text { Without } \\
\text { control }\end{array}$ & LQR-Control & $\begin{array}{l}\text { With } \\
\text { Kalman }\end{array}$ & LQG+Feedback Control \\
\hline $\begin{array}{l}P=1, Q=0.25 \\
\text { pu. } \\
\text { Lag p.f load }\end{array}$ & $\begin{array}{l}-0.0367+6.9961 i \\
-0.0367-6.9961 i \\
-14.2953 \\
-12.4821 \\
-2.7625 \\
-3.7201\end{array}$ & $\begin{array}{l}-1.1161+7.2542 \mathrm{i} \\
-1.1161-7.2542 \mathrm{i} \\
-43.3537 \\
-14.2787 \\
-5.6556 \\
-2.9596\end{array}$ & $\begin{array}{l}-7.24+10.0732 \mathrm{i} \\
-7.24-10.0732 \mathrm{i} \\
-14.3023 \\
-12.4881 \\
-3.7076 \\
-2.8026\end{array}$ & $\begin{array}{l}-7.2411+10.0732 \mathrm{i} \\
-7.2411-10.0732 \mathrm{i} \\
-1.1161+7.2542 \mathrm{i} \\
-1.1161-7.2542 \mathrm{i} \\
-43.3537 \\
-14.3023 \\
-14.2787 \\
-12.4881 \\
-5.6556 \\
-3.7076 \\
-2.8026 \\
-2.9596\end{array}$ \\
\hline $\begin{array}{l}P=1, Q=-0.25 \\
\text { pu } \\
\text { Lead p.f }\end{array}$ & $\begin{array}{l}0.1033+6.3047 i \\
0.1033-6.3047 i \\
-14.9008 \\
-12.4804 \\
-2.4303 \\
-3.7285\end{array}$ & $\begin{array}{l}-1.2812+6.6267 i \\
-1.2812-6.6267 i \\
-6.1062 \\
-1.5921 \\
-43.3498 \\
-14.8640\end{array}$ & $\begin{array}{l}-2.28+6.6889 \mathrm{i} \\
-2.28-6.6889 \mathrm{i} \\
-3.7220 \\
-2.3389 \\
-14.9022 \\
-12.4809\end{array}$ & $\begin{array}{l}-1.2812+6.6267 \mathrm{i} \\
-1.2812-6.6267 \mathrm{i} \\
-2.2857+6.6889 \mathrm{i} \\
-2.2857-6.6889 \mathrm{i} \\
-14.9022 \\
-14.8640 \\
-12.4809 \\
-6.1062 \\
-1.5921 \\
-2.3389 \\
-3.7220 \\
-43.3498\end{array}$ \\
\hline
\end{tabular}

Figure 5 shows the rotor angle deviation response due to 0.1 load disturbance with and without LQG and LQR controllers at lag power factor load ( $\mathrm{P}=1, \mathrm{Q}=0.25 \mathrm{pu})$. Fig.6 depicts the rotor speed deviation response due to 0.1 load disturbance with and without LQG and LQR controllers at lag power factor load $(\mathrm{P}=1, \mathrm{Q}=0.25 \mathrm{pu})$. Fig. 7 shows the rotor speed deviation response due to 0.1 load disturbance with LQG compared with LQR controllers at lag power factor load $(\mathrm{P}=1, \mathrm{Q}=0.25 \mathrm{pu})$. Fig. 8 displays the rotor speed deviation response due to 0.1 load disturbance with LQG compared with LQR controllers at lead power factor load $(\mathrm{P}=1, \mathrm{Q}=-0.25 \mathrm{pu})$. Fig. 9 shows the rotor speed deviation response due to 0.1 load disturbance with and without LQG and LQR controllers at lead power factor load $(\mathrm{P}=1, \mathrm{Q}=-$ $0.25 \mathrm{pu}$ ).Moreover, Table 3 displays the Eignvalues with and without controllers for single machine power system. Also, Table 4 shows the Settling time for single machine model with and without controllers 


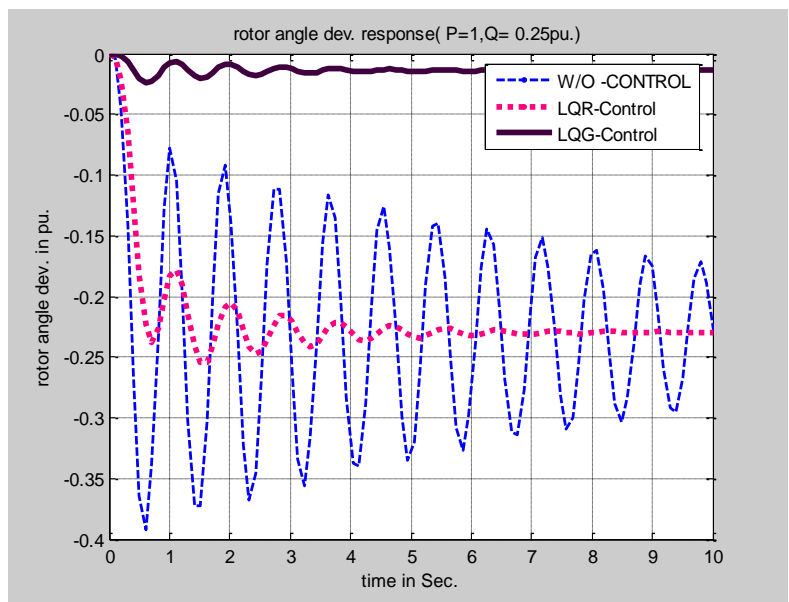

Fig.5: Rotor angle Response with and without LQG and LQR controllers $(\mathrm{P}=1, \mathrm{Q}=0.25 \mathrm{pu})$.

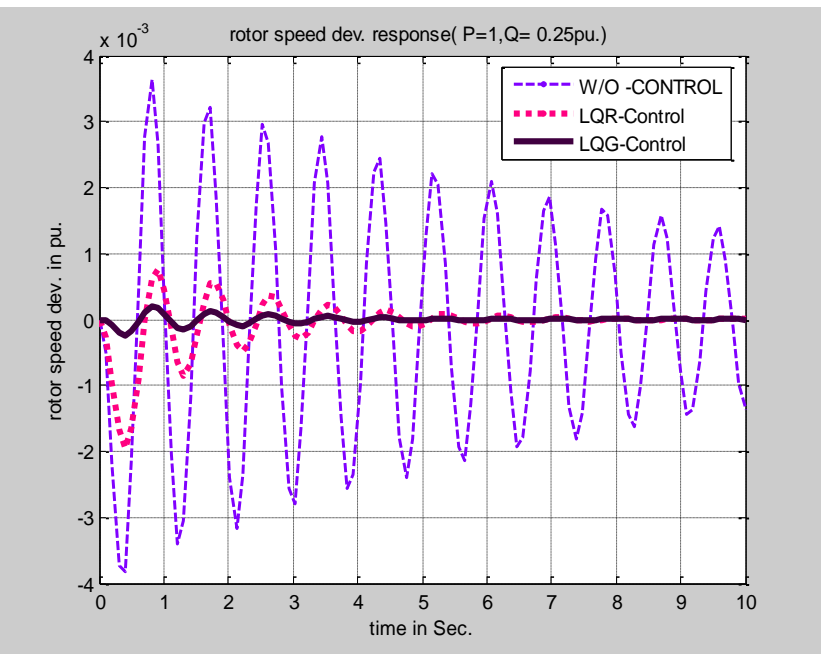

Fig.6: Rotor speed. Response with and without LQG and LQR controllers $(\mathrm{P}=1, \mathrm{Q}=0.25 \mathrm{pu})$.

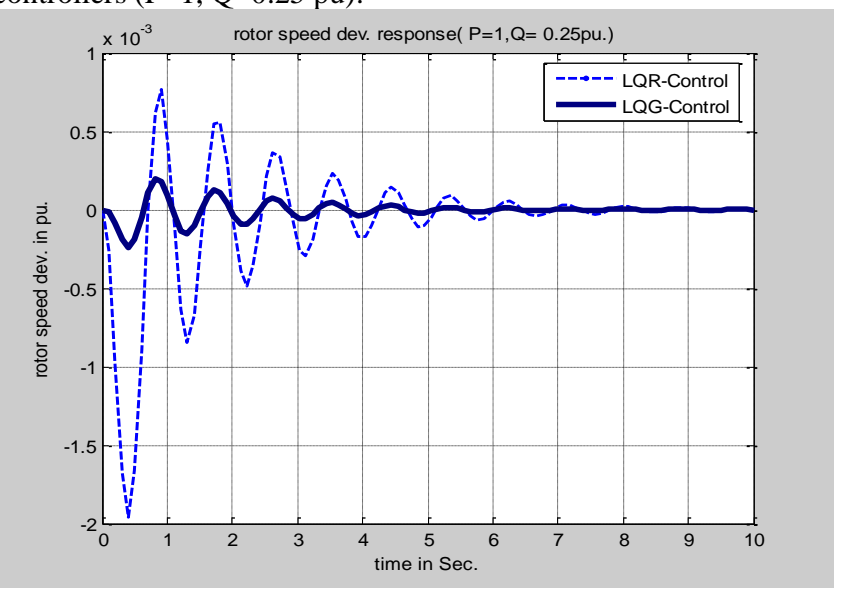

Fig. 7: Rotor speed. Response with LQG compared with LQR controller $(\mathrm{P}=1, \mathrm{Q}=0.25 \mathrm{pu})$.

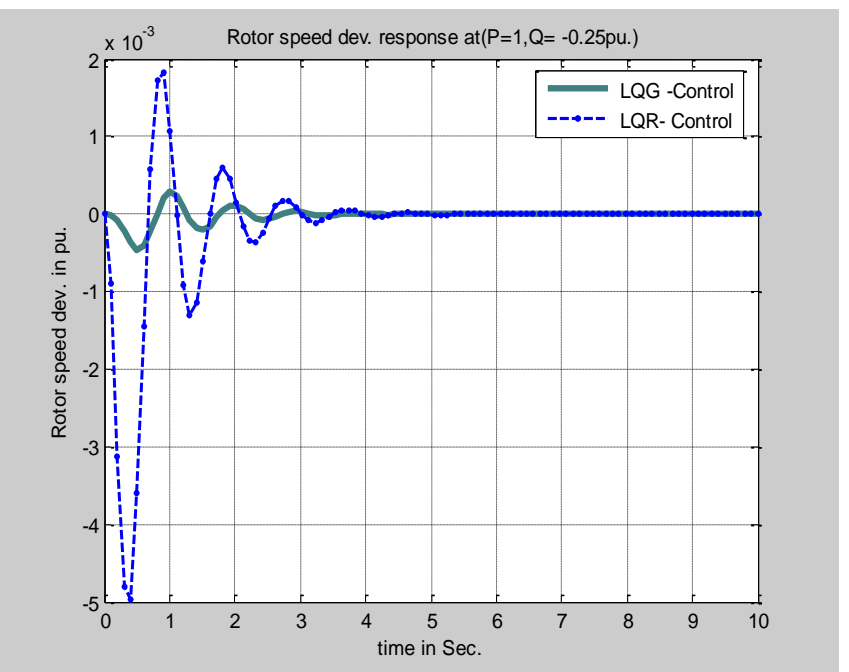

Fig. 8: Rotor speed. Response with LQG compared with LQR controller $(\mathrm{P}=1, \mathrm{Q}=-0.25 \mathrm{pu})$.

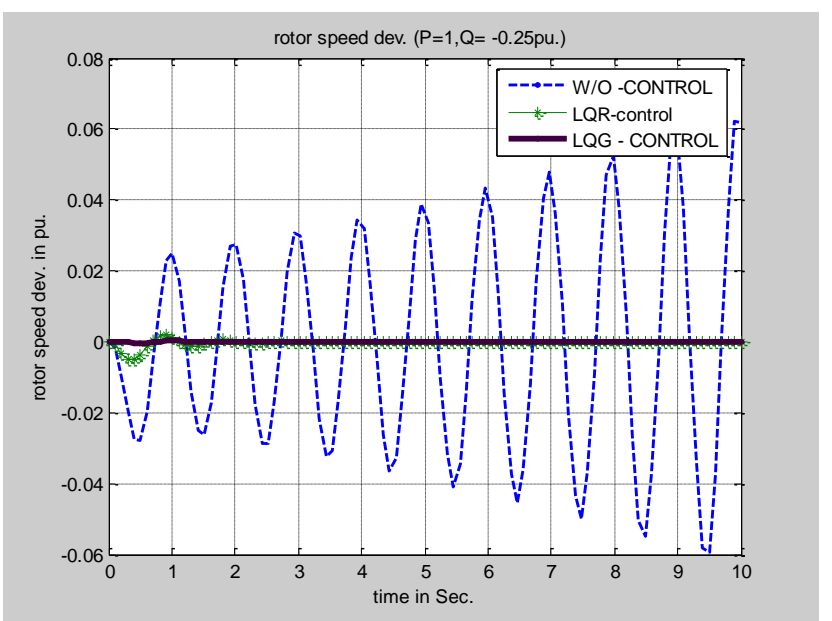

Fig. 9: Rotor speed. Response due with and without LQG and LQR controllers $(\mathrm{P}=1, \mathrm{Q}=-0.25 \mathrm{pu})$.

Table 4: Settling time with and without controllers

\begin{tabular}{|l|l|l|l|l|}
\hline & States & $\begin{array}{l}\text { Without } \\
\text { Control }\end{array}$ & $\begin{array}{l}\text { LQR- } \\
\text { Control }\end{array}$ & $\begin{array}{l}\text { LQG- } \\
\text { Control }\end{array}$ \\
\hline \hline $\begin{array}{l}\mathrm{P}=1, \\
\mathrm{Q}=0.25 \\
\text { pu. }\end{array}$ & $\begin{array}{l}\text { Rotor } \\
\text { Speed }\end{array}$ & $>10$ Sec. & 7 Sec. & 4 Sec. \\
\cline { 2 - 5 } & $\begin{array}{l}\text { Rotor } \\
\text { Angle }\end{array}$ & $>10$ Sec. & 5 Sec. & 2.5 Sec. \\
\hline \hline $\begin{array}{l}\mathrm{P}=1, \mathrm{Q}= \\
-0.25 \text { pu. }\end{array}$ & $\begin{array}{l}\text { Rotor } \\
\text { Speed }\end{array}$ & $\infty$ & 3.5 Sec. & 2 Sec. \\
\cline { 2 - 5 } & $\begin{array}{l}\text { Rotor } \\
\text { Angle }\end{array}$ & $\infty$ & 2 Sec. & 0.5 Sec. \\
\hline \hline
\end{tabular}




\subsection{Multi-machine Simulation results}

From LQR control (Eqn. 10), the feedback gain is:

$K_{\text {LQR }}=\left[\begin{array}{cccccccccccc}-0.3427 & -0.9033 & -6.1716 & 0.0007 & -0.0034 & 0.1117 & 0.0077 & 0.0023 & 0.0222 & 0.0004 & 0.0001 & 0.0033 \\ -0.1203 & -0.3101 & -5.3269 & -0.0314 & 0.2118 & -0.0105 & 0.0051 & 0.0232 & 0.0090 & 0.0004 & 0.0171 & 0.0005 \\ -0.0014 & -0.0060 & -0.0310 & -0.0000 & 0.0001 & 0.0002 & 0.0000 & 0.0000 & 0.0001 & 0.0000 & 0.0000 & 0.0000\end{array}\right]$

From LQG and Kalman filter control (Eqn. 13), the observer gain matrix $L$ and solution of reccati equation $\mathrm{P}$ for multimachine power system are calculated as:

$$
\mathrm{P}=1.0 \mathrm{e}+005 *
$$

$\left[\begin{array}{llllllllllll}0.0001 & 0.0000 & 0.0000 & 0.0001 & 0.0004 & 0.0009 & 0.0005 & -0.0001 & -0.0000 & 0.0011 & 0.0027 & 0.0026\end{array}\right.$ $\begin{array}{llllllllllll}0.0000 & 0.0001 & 0.0000 & -0.0003 & 0.0001 & 0.0010 & -0.0007 & -0.0023 & -0.0005 & 0.0030 & -0.0041 & 0.0041\end{array}$ $\begin{array}{llllllllllll}0.0000 & 0.0000 & 0.0001 & -0.0009 & -0.0010 & 0.0002 & -0.0017 & -0.0027 & -0.0017 & -0.0016 & -0.0015 & -0.0002\end{array}$ $\begin{array}{llllllllllll}0.0001 & -0.0003 & -0.0009 & 0.2884 & 0.1248 & 0.1732 & 0.0556 & 0.1493 & 0.0834 & 0.1157 & 0.3554 & 0.3037\end{array}$ $\begin{array}{llllllllllll}0.0004 & 0.0001 & -0.0010 & 0.1248 & 0.3536 & 0.2411 & 0.1331 & 0.2132 & 0.1238 & 0.6116 & 1.5001 & 0.5219\end{array}$ $\begin{array}{llllllllllll}0.0009 & 0.0010 & 0.0002 & 0.1732 & 0.2411 & 0.5262 & 0.1730 & 0.3027 & 0.1688 & 0.9288 & 0.9817 & 1.1909\end{array}$ $\begin{array}{llllllllllll}0.0005 & -0.0007 & -0.0017 & 0.0556 & 0.1331 & 0.1730 & 0.1409 & 0.2372 & 0.1310 & 0.3025 & 0.4897 & 0.3297\end{array}$ $\begin{array}{llllllllllll}-0.0001 & -0.0023 & -0.0027 & 0.1493 & 0.2132 & 0.3027 & 0.2372 & 0.5376 & 0.2360 & 0.3970 & 0.6862 & 0.4796\end{array}$ $\begin{array}{llllllllllll}-0.0000 & -0.0005 & -0.0017 & 0.0834 & 0.1238 & 0.1688 & 0.1310 & 0.2360 & 0.1333 & 0.2607 & 0.3948 & 0.2980\end{array}$ $\begin{array}{llllllllllll}0.0011 & 0.0030 & -0.0016 & 0.1157 & 0.6116 & 0.9288 & 0.3025 & 0.3970 & 0.2607 & 2.4141 & 2.8773 & 2.5029\end{array}$ $\begin{array}{llllllllllll}0.0027 & -0.0041 & -0.0015 & 0.3554 & 1.5001 & 0.9817 & 0.4897 & 0.6862 & 0.3948 & 2.8773 & 7.2526 & 2.3344\end{array}$ $\begin{array}{llllllllllll}0.0026 & 0.0041 & -0.0002 & 0.3037 & 0.5219 & 1.1909 & 0.3297 & 0.4796 & 0.2980 & 2.5029 & 2.3344 & 3.0502\end{array}$

$$
L=\left[\begin{array}{ccc}
5.6175 & 0.5023 & 0.5642 \\
0.5023 & 6.2919 & 0.7404 \\
0.5642 & 0.7404 & 5.1533 \\
5.5492 & -18.7586 & -61.8858 \\
29.3742 & 6.6030 & -64.0363 \\
57.6099 & 67.9089 & 10.6301 \\
31.0354 & -45.7872 & -109.9142 \\
-6.6915 & -153.5171 & -175.6031 \\
-2.9718 & -33.9607 & -114.5776 \\
74.3507 & 197.8533 & -103.3462 \\
180.2242 & -269.7776 & -97.1338 \\
169.9381 & 272.6171 & -16.0888
\end{array}\right]
$$

Figure 10 depicts the rotor speed deviation response due to 0.1 load disturbance with and without LQG control of M/C-1. Fig.11 shows the rotor speed deviation response due to 0.1 load disturbance with and without LQG control of M/C-2. Also, Fig.12 shows the rotor speed deviation response due to 0.1 load disturbance with LQG compared with LQR controllers of M/C-2. Fig. 13 depicts the rotor speed deviation response due to 0.1 load disturbance with and without LQG control of M/C-3. Moreover, Fig. 14 depicts the rotor speed deviation response due to $0.1 \mathrm{pu}$ load disturbance with LQR control for three machines.
Also, Fig. 15displays the rotor speed deviation response due to 0.1 pu load disturbance with LQG control for three machines. Table 5 displays the Settling time for multimachine model with and without controllers. Also, table 6 shows the Eignvalues calculation with and without controllers of multi- machine model

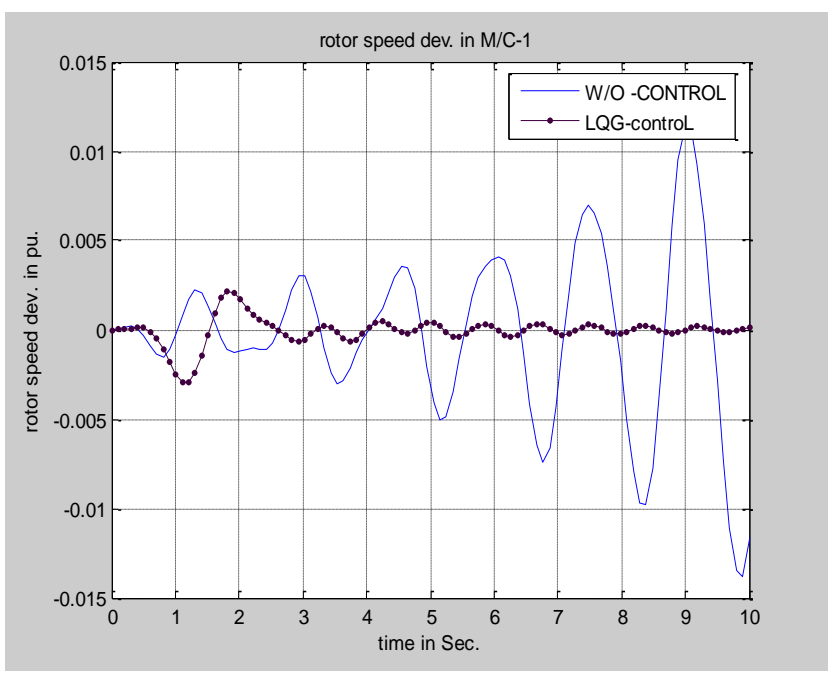

Fig. 10: Rotor speed. Response with and without LQG control of $\mathrm{M} / \mathrm{C}-1$.

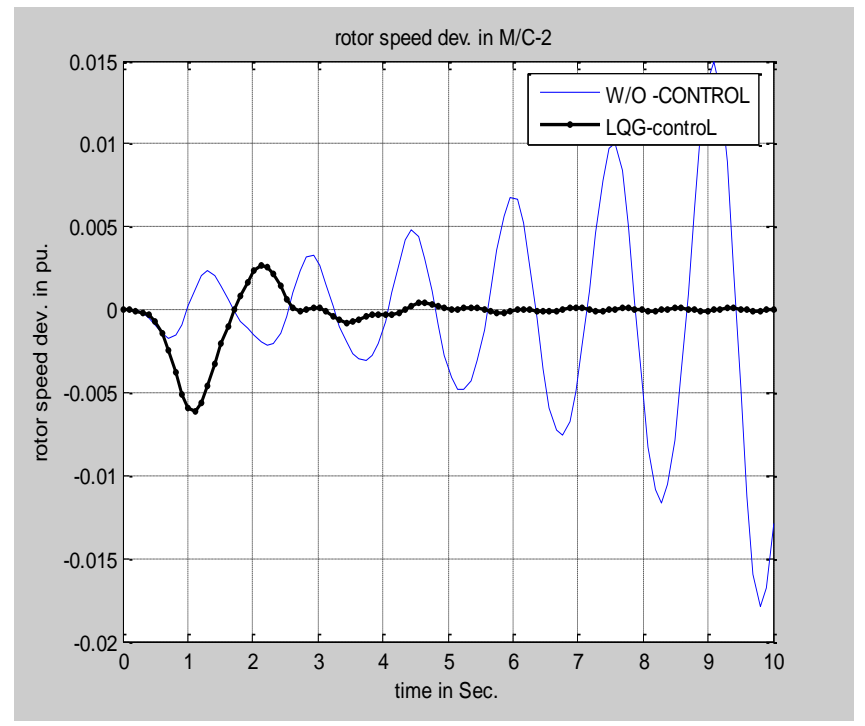

Fig.11: Rotor speed. Response with and without LQG control of $\mathrm{M} / \mathrm{C}-2$. 


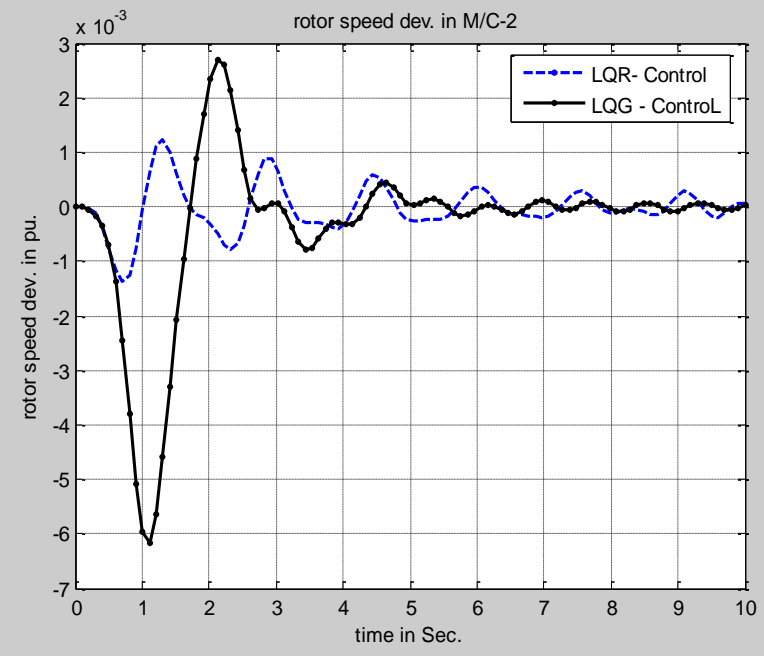

Fig.12: Rotor speed Response with LQG and LQR controllers of $\mathrm{M} / \mathrm{C}-2$.

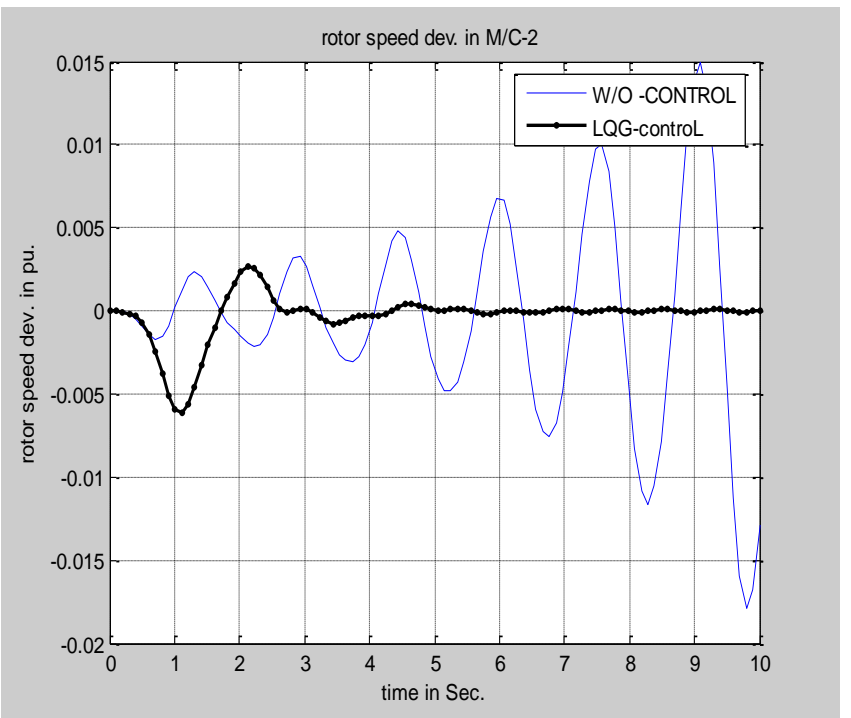

Fig. 13: Rotor speed. Response with and without LQG control of M/C-3.

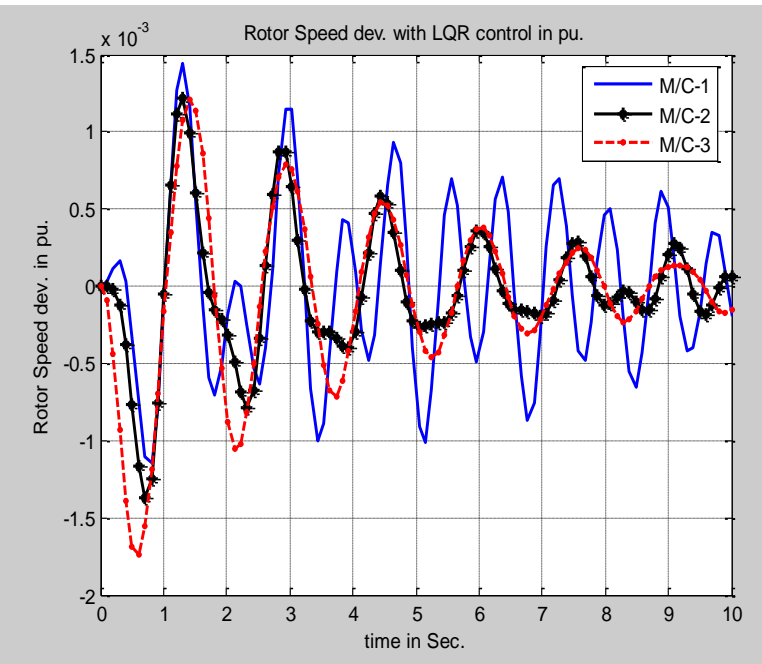

Fig. 14: Rotor speed. Response with LQR control for three machines.

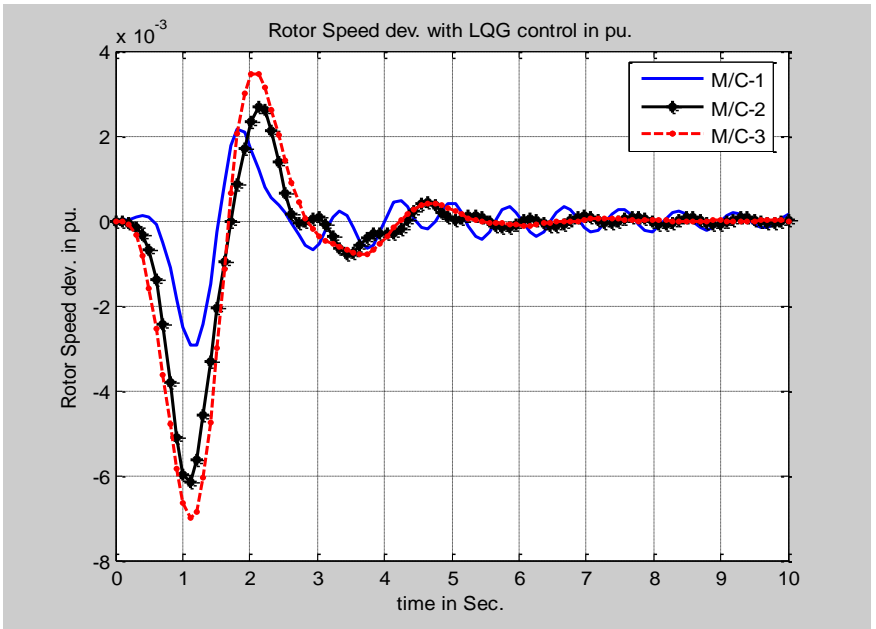

Fig. 16: Rotor speed. Response with LQG control for three machines. 
Table 5: Settling time for multi-machine model with and without controllers

\begin{tabular}{||l|l|l|l|l|}
\hline $\begin{array}{l}\text { Operating } \\
\text { Point }\end{array}$ & $\begin{array}{l}\text { Rotor } \\
\text { speed } \\
\text { of }\end{array}$ & $\begin{array}{l}\text { Without } \\
\text { controller }\end{array}$ & $\begin{array}{l}\text { With } \\
\text { LQR- } \\
\text { Control }\end{array}$ & $\begin{array}{l}\text { With } \\
\text { LQG }- \\
\text { Control }\end{array}$ \\
\hline \hline $\begin{array}{l}\mathrm{P}=1, \\
\mathrm{Q}=0.25 \\
\mathrm{pu}\end{array}$ & $\begin{array}{l}\mathrm{M} / \mathrm{C}- \\
1\end{array}$ & $\infty$ & $12 \mathrm{Sec}$. & $7 \mathrm{Sec}$. \\
\cline { 2 - 5 } & $\begin{array}{l}\mathrm{M} / \mathrm{C}- \\
2\end{array}$ & $\infty$ & 9 Sec. & $5.5 \mathrm{Sec}$. \\
\cline { 2 - 5 } & $\mathrm{M} / \mathrm{c}-3$ & $\infty$ & $5 \mathrm{Sec}$. & $3 \mathrm{Sec}$ \\
\hline
\end{tabular}

Table 6 shows an improvement in the stability margins with the Linear Quadratic Gaussian controller(LQG) compared with that of the Linear Quadratic Regulator (LQR) controller. Kalman Filter is used with the regulator LQR to produce the LQG. Also, Table 5 displays a decrease in the settling time for three machines with LQG controller than the other controller. Moreover, the three machines are unstable with the (LQR) while this is not the the case with the proposed LQG controller .

\section{Discussions}

Table 6: Eigen values calculation with and without controllers of multi- machine model

\begin{tabular}{|c|c|c|c|c|c|}
\hline & Without control & With LQR & With Kalman & With LQG & $\begin{array}{l}\text { With LQG + } \\
\text { Feedback control }\end{array}$ \\
\hline $\begin{array}{l}\text { Certain } \\
\text { Operating } \\
\text { Point }\end{array}$ & $\begin{array}{l}-18.8713 \\
-15.1893 \\
-17.0519 \\
0.0953+7.8364 \mathrm{i} \\
0.0953-7.8364 \mathrm{i} \\
-0.0627+7.3692 \mathrm{i} \\
-0.0627-7.3692 \mathrm{i} \\
0.2637+4.0915 \mathrm{i} \\
0.2637-4.0915 \mathrm{i} \\
-5.8914 \\
-3.4305 \\
-1.5112\end{array}$ & $\begin{array}{l}-34.1322 \\
-19.5804 \\
-15.7307 \\
-0.0721+7.8603 \mathrm{i} \\
-0.0721-7.8603 \mathrm{i} \\
-0.0776+7.3715 \mathrm{i} \\
-0.0776-7.3715 \mathrm{i} \\
-0.2581+4.0793 \mathrm{i} \\
-0.2581-4.0793 \mathrm{i} \\
-5.5632 \\
-3.0683 \\
-1.1913\end{array}$ & $\begin{array}{l}-18.8684 \\
-17.0507 \\
-15.1612 \\
-2.7296+7.4647 \mathrm{i} \\
-2.7296-7.4647 \mathrm{i} \\
-2.8210+7.0795 \mathrm{i} \\
-2.8210-7.0795 \mathrm{i} \\
-6.4027 \\
-2.4204+2.8257 \mathrm{i} \\
-2.4204-2.8257 \mathrm{i} \\
-3.4688 \\
-1.5217\end{array}$ & $\begin{array}{l}-34.1388 \\
-19.6481 \\
-15.7647 \\
-2.9275+7.5560 \mathrm{i} \\
-2.9275-7.5560 \mathrm{i} \\
-2.8056+7.1482 \mathrm{i} \\
-2.8056-7.1482 \mathrm{i} \\
-4.1097+3.2205 \mathrm{i} \\
-4.1097-3.2205 \mathrm{i} \\
-4.7248 \\
-2.0980 \\
-1.0843\end{array}$ & $\begin{array}{l}-34.1250 \\
-19.5046 \\
-18.8652 \\
-17.0493 \\
-15.6930 \\
-15.1210 \\
-0.2888+7.9098 \mathrm{i} \\
-0.2888-7.9098 \mathrm{i} \\
-0.0909+7.3805 \mathrm{i} \\
-0.0909-7.3805 \mathrm{i} \\
-2.4990+7.3546 \mathrm{i} \\
-2.4990-7.3546 \mathrm{i} \\
-2.8479+6.9797 \mathrm{i} \\
-2.8479-6.9797 \mathrm{i} \\
-0.9751+4.7816 \mathrm{i} \\
-0.9751-4.7816 \mathrm{i} \\
-7.5320 \\
-0.8193+2.4713 \mathrm{i} \\
-0.8193-2.4713 \mathrm{i} \\
-5.7117 \\
-3.6632 \\
-3.3731 \\
-1.2828 \\
-1.5345\end{array}$ \\
\hline
\end{tabular}

\section{Conclusion}

The present paper introduced an application of a robust linear quadratic Gaussian LQG controller to design a power system stabilizer. The LQG optimal control has been developed and tested using a power system comprises three machines. The results using the LQG controller show an improved performance in terms of fast damping oscillation dynamic, reduction in the rotor first swing and smaller settling time. The LQG has a superior performance over a wide range of operating conditions rather than LQR controller. The results are of prime importance to power system engineers forming a useful guide improve power system performance via a simple and constructive way 
[10]. P. P. Khargonekar, I. R. Petersen, and M. A. Rotea, "Hinf optimal control with state feedback," IEEE Trans. Automat. Contr., AC-33, pp. 783-

\section{References}

[1]. M. K. El-Sherbiny and D. Mehta " Dynamic 786, 1988. stability, part I, investigation of the effect of different loading and excitation system" IEEE Trans. Power Appar. Sys., PAS-92(1973), PP 1538-1546.

[2]. Chern-Lin Chen and Yuan Yih Hsu " Coordinated synthesis of multi machine power system stabilizer using an efficient decentralized modal control algorithm" IEEE Transaction on power system, vol. PWRS-2, No. 3, August 1987.

[3]. Lan Petersen, “ Minimax LQG control”, School of information technology and electrical engineering, university of New south Wales, Australia, Vol 16, No. 3, PP. 209:323, 2006.

[4]. M. K. El-Sherbiny, A.I.Saleh and A.A.M.ElGaafary " Optimal Design of An

Overall Controller of Saturated Synchronous Machine Under Different Loading", EEE Transaction of power Apparatus and System, Vol.PAS-102,No.6,June 1983.

[5]. M.K. El-Sherbiny , G.El-Saady and Ali M. Yousef "Robust controller for power system stabilization" IEEE MEPCON'2001, Helwan University, Cairo, Egypt, December 29-31,2001, PP. 287-291.

[6]. M.K. El-Sherbiny , M. M. Hassan, G.El-Saady and Ali M. Yousef " Optimal pole shifting for power system stabilization", Electric Power Systems Research Journal, No.66 PP. 253-258. 2003.

[7]. S. C. Tripathy, R. Balasubramanian and Zahid Jamil " Interaction of Voltage and

Frequency Control Loops and Optimization of Parameters", IE(I) Journal-EL, Vol. 62, paper No. UDC 621-316-2, October 1981.

[8]. J. Doyle, K. Glover, P. Khargonekar, and B. Francis, "State-space solutions to standard H2 and Hinf control problems," IEEE Trans. Automat. Contr., AC-34, no. 8, PP. 831-847, Aug. 1989.

[9]. Ali M. Yousef, and Amer Abdel-Fatah " A robust $H_{\infty}$ synthesis controller for power system stabilization " International journal of automatic control and system engineering Vol.2, pp. 1-6, Feb. 2005, Germany.

Engineering Research Journal, Minoufiya University, Vol. 36, No. 2, April 2013 